\title{
Prosedur Strategis Untuk Mengurangi Level Bahaya Arc-Flash Pada Medium Voltage Dengan Metode Koordinasi Proteksi Di PT Ipmomi Paiton
}

\author{
Inas Ratnaning Zafirah, Margo Pujiantara, Arif Musthofa \\ Jurusan Teknik Elektro, Fakultas Teknologi Industri, Institut Teknologi Sepuluh Nopember (ITS) \\ Jl. Arief Rahman Hakim, Surabaya 60111 Indonesia \\ e-mail: margo@ee.its.ac.id, inasratnaningzafirah@yahoo.com
}

\begin{abstract}
Abstrak-Di area sistem kelistrikan, operasi, dan maintenance, perhatian terbesar adalah keselamatan dan keamanan pekerja yang mengoperasikan dan menjaga sistem. Sistem kelistrikan didisain tidak hanya untuk tindakan pencegahan yang diperlukan pada sistem proteksi dan peralatan, tetapi juga harus memperhatikan keselamatan personal untuk tingkat tertentu dari arc-flash atau busur api karena arcing fault. Pada tugas akhir ini, bahaya busur api akan dianalisis dan diperhitungkan. Hasilnya akan diketahui level energi arc-flash atau busur api yang mungkin terjadi sesuai standar NFPA 70E-2004. Data yang nanti digunakan diambil dari plant yang telah ditentukan sebelumnya yaitu PT IPMOMI. Dari data tersebut, parameter - parameter yang diperlukan akan dihitung dan diketahui level busur api. Bila diperlukan, maka juga akan dilakukan resetting atau penambahan rele over current.
\end{abstract}

Kata kunci-busur api, personal protective equipment, overcurrent protective device

\section{PENDAHULUAN}

$S_{\mathrm{k}}^{\mathrm{L}}$ UATU sistem pengaman harus mampu bekerja pada kondisi dan setting yang telah ditentukan sebelumnya. dimana sistem pengaman mempunyai peranan yang sangat penting dalam mengamankan suatu jaringan atau plant industri. Sistem pengaman juga berperan dalam keandalan dari suatu jaringan atau plant. Salah satu faktor yang juga ikut dihitung dalam penentuan setting sistem pengaman adalah adanya bahaya arc flash atau busur api.

Fenomena busur api, dapat terjadi pada suatu jaringan atau plant industri. Dimana busur api ini melepaskan energi dan arus yang sangat besar hingga membahayakan peralatan disekitar wilayah yang terdampak dan bahkan membahayakan nyawa pekerja disekitarnya. Studi mengenai bahaya arc flash, menggunakan analisis short circuit dan analisis koordinasi peralatan pengaman pada plant yang bersangkutan. Sehingga, dengan melakukan perhitungan arcing current dan incident energi akan diketahui level energi bahaya arc- flash yang mungkin terjadi pada sistem, dan pemilihan peralatan pengaman dapat diperhitungkan untuk mengurangi level bahaya energi arc-flash tersebut.

\section{LANDASAN TEORI}

\section{A. Pengertian Busur Api (Arc Flash)}

Busur api atau arc flash merupakan suatu fenomena yang berbahaya, dimana kejadian ini disertai dengan adanya pelepasan energi yang disebabkan oleh arcing listrik [1]. Busur api yang terjadi, dapat menghasilkan temperatur udara disekitarnya menjadi $35000^{\circ} \mathrm{F}$. Terjadinya busur api ini, juga diikuti oleh kilatan cahaya yang dapat mengganggu penglihatan dan bahkan juga dapat merusak mata seseorang. Selain itu, busur api juga dapat menghasilkan ledakan yang sangat keras serta dapat menyebabkan luka bakar bagi pekerja yang terpapar didaerah kejadian [3].

Beberapa hal yang dapat menyebabkan terjadinya peristiwa busur api antara lain:

- Debu, pengaratan, binatang.

- Spark discharge dari sentuhan/ peralatan yang terjatuh.

- Kegagalan isolasi dari peralatan

- Kegagalan kerja peralatan pengaman

Faktor-faktor yang dapat mempengaruhi besarnya energi arc flash yang dapat terjadi diantaranya adalah level tegangan, jarak antar konduktor, dan juga waktu kerja rele untuk mengisolasi gangguan yang terjadi [2].Selain itu, besar energi busur api yang dihasilkan tergantung dariwaktu kerja sistem pengaman akibat gangguan arus hubung singkat. Semakin cepat rele pengaman bekerja semakin kecilpula busur api yang dihasilkan dan berlaku sebaliknya. Oleh karena itu, studi untuk mengetahui besar energi busur api yangdihasilkan pada masing-masing switchgear perlu dilakukan untuk memberikan peringatan kepada para pekerja maupun orang disekitarnya akan dampak yang ditimbulkan serta perlengkapan keselamatan yang harus dikenakan sebagai langkah pencegahan agar terhindar dari jatuhnya korban jiwa [4].

B. Perhitungan Energi Busur Api Menggunakan Standart IEEE 1584-2002 [1]

Pada metode ini, hal pertama yang harus diperhitungkan adalah mencari nilai dari arus arcing fault. Persamaan 
untuk menghitung dari arus arcing fault sendiri, ada 2, yaitu tergantung dari besarnya level tegangan bus.

Untuk level tegangan kurang dari $1 \mathrm{kV}$, persamaan arus arcing faultnya adalah:

$$
\begin{aligned}
& \lg I_{a}=K+0,662 \lg I_{b f}+0,0966 V+0,000526 G+ \\
& 0,5588 V\left(\lg I_{b f}\right)-0,00304 G\left(\lg I_{b f}\right)
\end{aligned}
$$

Sementara untuk level tegangan $1 \mathrm{kV}-15 \mathrm{kV}$, perhitungan arus arcing faultnya menggunakan persamaan:

$$
\lg I \mathrm{a}=0,00402+0,983 \lg I_{b f}
$$

Lalu nilai Ia dapat diperoleh:

$$
\text { Ia }=10 \lg I a
$$

\section{Dimana:}

$\lg =\log _{10}$

$I_{a} \quad=$ arus $\operatorname{arcing}(\mathrm{kA})$

$K=$ konstanta untuk konfigurasi terbuka $=-0,153$ dan konstanta untuk konfigurasi box $=-0,097$

$\lg I_{b f}=$ bolted fault current pada gangguan tiga fase(symmetrical RMS) (kA)

$V \quad=$ tegangan sistem $(\mathrm{kV})$

$G \quad=$ jarak celah antar konduktor $(\mathrm{mm})$

Setelah nilai arcing current diketahui maka nilai dari incident energi normalisasi dapat dihitung. Dalam perhitungan besar energi yang normal, menggunakan referensi waktu arcing dengan durasi 0,2 detik dan jarak dari titik arcing ke manusia sebesar $610 \mathrm{~mm}$. Persamaan yang digunakan adalah :

$$
\lg E n=\mathrm{K} 1+\mathrm{K} 2+1,081 \lg I a+0,0011 \mathrm{G}
$$

Dimana:

$E_{n}=$ incident energy normalized $\left(\mathrm{J} / \mathrm{cm}^{2}\right)$

$\mathrm{K} 1=-0,792$ untuk konfigurasi terbuka (no enclosure);

$-0,555$ untuk konfigurasi box (enclosed equipment)

$\mathrm{K} 2=0$ untuk sistem ungrounded and high-resistance grounded;

$-0,113$ untuk sistem grounded

$\mathrm{G}=$ jarak/celah antar konduktor $(\mathrm{mm})$

Untuk mendapatkan nilai $G$ (jarak antar konduktor) dapat mengikuti standar yang sudah ada. Peralatan yang digunakan dalam sistem kelistrikan. Dalam tabel 2.1 dijelaskan untuk jarak celah bus pada beberapa peralatan lain dengan referensi dari IEEE 1584-2002.

Setelah itu besar energi $E_{n}$ dapat diketahui:

$$
E_{n}=10^{\operatorname{lgEn}}
$$

Setelah nilai $E_{n}$ didapatkan, untuk menghitung besar insiden energi $\mathrm{E}$ digunakan persamaan :

$$
\mathrm{E}=4,184 C_{f} E_{n}\left(\frac{t}{0,2}\right)\left(\frac{610^{x}}{D^{x}}\right)
$$

Tabel 1.

Tabel data jarak celah bus (Jarak Bus) [1]

\begin{tabular}{ll}
\hline \hline Kelas Peralatan & Jarak celah antar \\
& konduktor $(\mathrm{mm})$ \\
\hline 6-15kV Switchgear & 153 \\
$5 k V$ Switchgear & 102 \\
Low voltage switchgear & 32 \\
Low voltages MCCs and panelboards & 25 \\
Cable & 13 \\
Other & Not required \\
\hline \hline
\end{tabular}

Dimana:

$\mathrm{E}=$ incident energy $(\mathrm{J} / \mathrm{cm} 2)$

$C_{f}=$ faktor pengali

1,0 untuk tegangan diatas $1 \mathrm{kV}$, dan

1,5 untuk tegangan dibawah $1 \mathrm{kV}$

$E_{n}=$ incident energy normalized

$T=$ waktu $\operatorname{arcing}$ (detik)

$D=$ jarak kerja $(\mathrm{mm})$

$X=$ jarak exponent

Untuk memenuhi semua parameter-parameter dalam menghitung besarnya insiden energi (E) dapat melihat pada tabel 2.2.Parameter yang dapat dicari dalam tabel ini yaitu jarak celah antar konduktor $(\mathrm{G})$, jarak eksponen (x), dan jarak kerja (D). Adapun nilai dari parameter-parameter yang dimaksud adalah sebagai berikut:

Tabel 2.

Tabel data parameter-paremeter yang dibutuhkan untuk perhitungan insiden energi

\begin{tabular}{clccc}
\hline \hline $\begin{array}{c}\text { Level } \\
\text { Tegangan } \\
(\mathrm{kV})\end{array}$ & $\begin{array}{c}\text { Jenis } \\
\text { Peralatan }\end{array}$ & $\begin{array}{c}\text { Jarak celah } \\
\text { antar } \\
\text { konduktor } \\
(\mathrm{mm})\end{array}$ & $\begin{array}{c}\text { Jarak } \\
\text { eksponent }\end{array}$ & $\begin{array}{c}\text { Jarak kerja } \\
(\mathrm{mm})\end{array}$ \\
\hline \multirow{3}{*}{$0,208-1$} & Open air & $10-40$ & 2 & - \\
\cline { 2 - 5 } & Switchgear & 32 & 1,473 & 455 \\
\cline { 2 - 5 } & $\begin{array}{l}\text { MCC and } \\
\text { panels }\end{array}$ & 25 & 1,641 & 455 \\
\cline { 2 - 5 } & Cable & 13 & 2 & 455 \\
\hline \multirow{3}{*}{$>1-5$} & Open air & 102 & 2 & - \\
\cline { 2 - 5 } & Switchgear & $13-102$ & 0,973 & 610 \\
\cline { 2 - 5 } & Cable & 13 & 2 & 455 \\
\hline Open air & $13-153$ & 2 & - \\
\cline { 2 - 5 } & Switchgear & 153 & 0,973 & 910 \\
\cline { 2 - 5 } & Cable & 13 & 2 & 455 \\
\hline \hline
\end{tabular}

Jumlah energi yang dihasilkan arc-flash tergantung dari level tegangan tempat arus gangguan terjadi, jarak pekerja dengan sumber arcing dan waktu yang dibutuhkan peralatan pengaman arus lebih untuk menghilangkan dan mengisolir gangguan.

\section{Jarak Aman Perlindungan}

Persamaan untuk perhitungan jarak aman perlindungan berdasarkan IEEE 1584 mengacu pada besarnya insiden energi normalisasi dari busur api. Namun ketika menggunakan analisa metode kurva batas energi, nilai tepat mngenai insiden energi normalisasi tidak dihitung. Bagaimanapun akhirnya untuk menghitung jarak aman pekerja tetap harus dilakukan. Perhitungannya kali ini 
mengacu pada besarnya nilai insiden energi pada tiap-tiap kategori. Sehingga yang diperoleh adalah nilai jarak maksimum untuk setiap masing-masing kategori.

Perhitungan level insiden energi ( $\left.\mathrm{E}_{\mathrm{WD}}\right)$ untuk sistem tegangan antara $1-15 \mathrm{kV}$ pada jarak kerja $\left(\mathrm{D}_{\mathrm{WD}}\right)$ adalah :

$$
E W_{D}=4,184 \mathrm{C}_{\mathrm{f}} \operatorname{En}\left(\frac{\mathrm{t}}{0,2}\right)\left(\frac{610^{\mathrm{x}}}{\mathrm{D}^{\mathrm{x}} W \mathrm{D}}\right)
$$

Sedangkan perhitungan level insiden energi $\left(E_{B}\right)$ pada jarak aman perlindungan $\left(\mathrm{D}_{\mathrm{B}}\right)$ adalah.

$$
E_{B}=4,184 \mathrm{C}_{\mathrm{f}} \operatorname{En}\left(\frac{\mathrm{t}}{0,2}\right)\left(\frac{610^{\mathrm{x}}}{\mathrm{D}^{\mathrm{x}} \mathrm{B}}\right)
$$

Jika persamaan (2.17) diatas dibagi dengan persamaan (2.18) maka :

$$
\frac{E_{B}}{E_{W D}}=\left(\frac{D_{B}}{D_{W D}}\right)^{-x}
$$

Sehingga untuk mencari jarak aman tiap kategori PPE:

$$
D_{B}=\frac{D_{W D}}{\sqrt[x]{\frac{E_{B}}{E_{W D}}}}
$$

Sedangkan untuk sistem lebih dari $15 \mathrm{kV}$ sebagai berikut:

$$
D_{B}=\frac{D_{W D}}{\sqrt[2]{\frac{E_{B}}{E_{W D}}}}
$$

\section{SISTEM KELISTRIKAN PT. LINDE}

PT. IPMOMI PAITON berada di desa Bhinor, kecamatan Paiton, provinsi Jawa Timur. Seperti pada gambar 1, lebih tepatnya di areal pembangkit listrik PLN Jl. Raya Surabaya - Situbondo Km. 141. Letak geografis PT. IPMOMI berada di pesisir pantai Utara Pulau Jawa, yang berdekatan dekat Selat Madura. $142 \mathrm{~km}$ ke arah tenggara Surabaya.

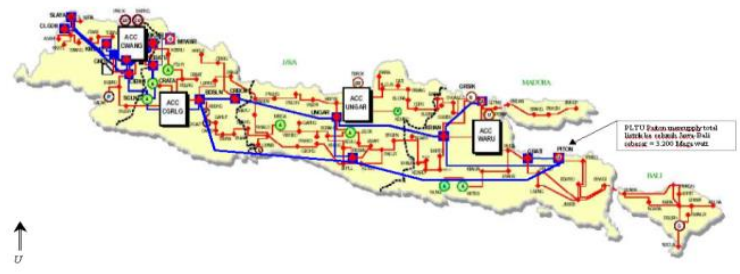

Gambar 1. Peta Lokasi PLTU Paiton-probolinggo

PT IPMOMI PAITON memiliki dua unit pembangkit yang menggunakan mesin turbogenerator berbahan bakar batubara dengan kapasitas 2 x $615 \mathrm{MW}$. Unit tersebut beroperasi dengan rata-rata $83 \%$ capacity factor pertahun dan memproduksi listrik rata-rata 8.943.084 MW per tahun, serta mengkonsumsi batubara 4,3 juta ton per tahun. Generator pada PT IPMOMI digunakan untuk menyuplai listrik ke jaringan ekstra tinggi $500 \mathrm{kV}$ dan dipakai untuk pemakaian sendiri dimana tegangan output generator diturunkan melalui transformer sesuai dengan kebutuhan. Untuk kebutuhan saat start diambilkan dari $150 \mathrm{kV}$ dari PLN. Pada sistem tegangan ekstra tinggi tenaga listrik yang dihasilkan oleh power plant disuplai ke jaringan sebesar $500 \mathrm{kV}$ dan selanjutnya beberapa transformer tegangannya diturunkan sesuai dengan kebutuhan. Adapun sistem kelistrikan perusahaan ini dapat dilihat pada gambar2.

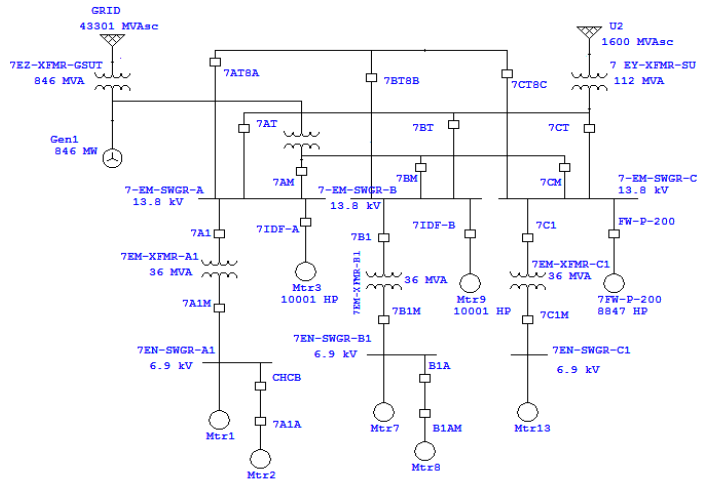

Gambar 2. Sistem Kelistrikan PT IPMOMI PAITON

\section{HASIL SIMULASI DAN ANALISA}

\section{A. Hasil Simulasi Busur Api}

Simulasi perangkat lunak ETAP menggunakan perhitungan berdasarkan standar IEEE 1584-2002. Simulasi dilakukan pada tegangan menengah $13.8 \mathrm{KV}$ dan 6.9 KV di sistem kelistrikan PT IPMOMI PAITON. Berikut akan ditampilkan besarnya energi busur api (arc flash) pada bus-bus dengan koordinasi proteksi existing. Data-data berikut berisikan Bus ID, besarnya arus bolted fault, arus arching, FCT (Fault Clearing Time), Insiden Energi, dan Kategori Bahaya. Data berikut akan ditampilkan pada tabel 3 dimana level tegangan bus-bus nya adalah $13.8 \mathrm{KV}$ dan $6.9 \mathrm{KV}$.

Tabel 3

Data Hasil Simulasi Energi Busur Api Kondisi Eksisting pada PT IPMOMI PAITON

\begin{tabular}{ccccccc}
\hline \hline ID & $\begin{array}{c}\text { Tegangan } \\
\text { Bus } \\
(\mathrm{kV})\end{array}$ & $\begin{array}{c}\text { Arus } \\
\text { Bolted } \\
\text { Fault } \\
(\mathrm{KA})\end{array}$ & $\begin{array}{c}\text { Arus } \\
\text { Arching } \\
(\mathrm{KA})\end{array}$ & $\begin{array}{c}\text { FCT } \\
(\mathrm{s})\end{array}$ & $\begin{array}{c}\text { Insiden } \\
\text { Energi } \\
\left(\mathrm{cal} / \mathrm{cm}^{2}\right)\end{array}$ & $\begin{array}{c}\text { Energi } \\
\text { Levels }\end{array}$ \\
\hline $\begin{array}{c}\text { 7EMSW } \\
\text { GRA }\end{array}$ & 13.8 & 72.59 & 68.11 & 0.1 & 10.722 & Level 3 \\
7EMSW & 13.8 & 72.59 & 68.11 & 0.1 & 10.722 & Level 3 \\
$\begin{array}{c}\text { GRB } \\
\text { 7EMSW }\end{array}$ & 13.8 & 72.59 & 68.11 & 0.1 & 10.722 & Level 3 \\
$\begin{array}{c}\text { GRC } \\
\text { 7ENSW } \\
\text { GRA1 }\end{array}$ & 6.9 & 47.1 & 44.53 & 0.45 & 24.961 & Level 4 \\
7ENSW & 6.9 & 47.71 & 44.53 & 0.1 & 5.547 & Level 2 \\
$\begin{array}{c}\text { GRA1A } \\
\text { 7ENSW }\end{array}$ & 6.9 & 45.86 & 43.37 & 0.45 & 24.26 & Level 4 \\
$\begin{array}{c}\text { GRB1 } \\
\text { 7ENSW }\end{array}$ & 6.9 & 45.86 & 43.37 & 0.1 & 5.391 & Level 2 \\
$\begin{array}{c}\text { GRB1A } \\
\text { 7ENSW } \\
\text { GRC1 }\end{array}$ & 6.9 & 43.21 & 40.91 & 0.45 & 23.158 & Level 4 \\
\hline \hline
\end{tabular}

Tabel 4.

Data Hasil Simulasi Energi Busur Api Setelan Resetting di PT IPMOMI PAITON

\begin{tabular}{ccccccc}
\hline \hline ID & $\begin{array}{c}\text { Tegangan } \\
\text { Bus } \\
(\mathrm{kV})\end{array}$ & $\begin{array}{c}\text { Arus } \\
\text { Bolted } \\
\text { Fault } \\
(\mathrm{KA})\end{array}$ & $\begin{array}{c}\text { Arus } \\
\text { Arching } \\
(\mathrm{KA})\end{array}$ & $\begin{array}{c}\text { FCT } \\
(\mathrm{s})\end{array}$ & $\begin{array}{c}\text { Insiden } \\
\text { Energi } \\
\left(\mathrm{cal} / \mathrm{cm}^{2}\right)\end{array}$ & $\begin{array}{c}\text { Energi } \\
\text { Levels }\end{array}$ \\
\hline 7EMSWGRA & 13.8 & 72.59 & 68.11 & 0.11 & 11.93 & $\begin{array}{c}\text { Level } \\
3\end{array}$ \\
& & & 68.11 & $\begin{array}{c}6.11 \\
6\end{array}$ & 11.93 & $\begin{array}{c}\text { Level } \\
3\end{array}$ \\
7EMSWGRB & 13.8 & 72.59 & & & & \\
7EMSWGRC & 13.8 & 72.59 & 68.11 & 0.11 & 11.93 & Level \\
\hline \hline
\end{tabular}




\begin{tabular}{|c|c|c|c|c|c|c|}
\hline & & & & 6 & & 3 \\
\hline $\begin{array}{c}\text { 7ENSWGRA } \\
1\end{array}$ & 6.9 & 47.1 & 44.53 & $\begin{array}{c}0.11 \\
6\end{array}$ & 7.53 & $\begin{array}{l}\text { Level } \\
2\end{array}$ \\
\hline $\begin{array}{c}\text { 7ENSWGRA } \\
1 \mathrm{~A}\end{array}$ & 6.9 & 47.71 & 44.53 & $\begin{array}{c}0.11 \\
6\end{array}$ & 7.53 & $\begin{array}{c}\text { Level } \\
2\end{array}$ \\
\hline $\begin{array}{c}\text { 7ENSWGRB } \\
1\end{array}$ & 6.9 & 45.86 & 43.37 & $\begin{array}{c}0.11 \\
6\end{array}$ & 7.32 & $\begin{array}{c}\text { Level } \\
2\end{array}$ \\
\hline $\begin{array}{c}\text { 7ENSWGRB } \\
1 \mathrm{~A}\end{array}$ & 6.9 & 45.86 & 43.37 & $\begin{array}{c}0.11 \\
6\end{array}$ & 7.32 & $\begin{array}{c}\text { Level } \\
2\end{array}$ \\
\hline $\begin{array}{c}\text { 7ENSWGRC } \\
1\end{array}$ & 6.9 & 43.21 & 40.91 & $\begin{array}{c}0.11 \\
6\end{array}$ & 6.87 & $\begin{array}{c}\text { Level } \\
2\end{array}$ \\
\hline
\end{tabular}

B. Perhitungan Busur Api Menggunakan Standart IEEE 1584-2002

Dalam penentuan analisa busur api terlebih dahulu harus dicari besarnya arus gangguan bolted dan FCT (Fault Clearing Time) pada tiap-tiap bus. Arus gangguan bolted adalah arus hubung singkat tiga fase, $1 / 2$ cycle saat pembangkitan maksimum. Pada arus bolted ini, kontribusi arus dari beban juga ditambahkan. Sedangkan FCT adalah besarnya durasi waktu yang dibutuhkan rele untuk mengamankan gangguan.

\section{- $\quad$ BUS 7EMSWGRA}

Perhitungan arus arcing (Ia):

$\log \left(\mathrm{I}_{\mathrm{a}}\right)=0,00402+0,983 \log \left(\mathrm{I}_{\mathrm{B}}\right)$

$\log \left(I_{a}\right)=0,00402+0,983 \log (72.59)$

$\log \left(\mathrm{I}_{\mathrm{a}}\right)=1,833, \mathrm{I}_{\mathrm{a}}=68.11 \mathrm{kA}$

Perhitungan Insiden Energi (E):

$\mathrm{En}=10^{K 1+K 2+1,081 \log (I a)+0,0011 G}$

$\mathrm{En}=10^{-0,555+(-0.133)+1,081 \times 1,833+0,0011 \times 153}$

$\mathrm{En}=28.95 \mathrm{~J} / \mathrm{cm}^{2}$

Incident Energy $=4,184 \mathrm{C}_{\mathrm{f}} \operatorname{En}\left(\frac{\mathrm{t}}{0,2}\right)\left(\frac{610^{\mathrm{x}}}{\mathrm{D}^{\mathrm{x}}}\right)$

Incident Energy $=4,184 \times 1 \times 28.95\left(\frac{0,116}{0,2}\right)\left(\frac{610^{0,973}}{910^{0,973}}\right)$

Incident Energy $=47.61 \mathrm{~J} / \mathrm{cm}^{2}$

Incident Energy $=47.61 / 4,184$

Incident Energy $=11.38 \mathrm{cal} / \mathrm{cm}^{2}$

\section{- $\quad$ BUS 7EMSWGRB}

Perhitungan arus arcing (Ia):

$\log \left(\mathrm{I}_{\mathrm{a}}\right)=0,00402+0,983 \log \left(\mathrm{I}_{\mathrm{B}}\right)$

$\log \left(I_{a}\right)=0,00402+0,983 \log (72.59)$

$\log \left(I_{a}\right)=1,833, I_{a}=68.11 \mathrm{kA}$

Perhitungan Insiden Energi (E):

$\mathrm{En}=10^{K 1+K 2+1,081 \log (I a)+0,0011 G}$

$\mathrm{En}=10^{-0,555+(-0.133)+1,081 \times 1,833+0,0011 \times 153}$

$\mathrm{En}=28.95 \mathrm{~J} / \mathrm{cm}^{2}$

Incident Energy $=4,184 \mathrm{C}_{\mathrm{f}} \operatorname{En}\left(\frac{\mathrm{t}}{0,2}\right)\left(\frac{610^{\mathrm{x}}}{\mathrm{D}^{\mathrm{x}}}\right)$

Incident Energy $=4,184 \times 1 \times 28.95\left(\frac{0,116}{0,2}\right)\left(\frac{610^{0,973}}{910^{0,973}}\right)$

Incident Energy $=47.61 \mathrm{~J} / \mathrm{cm}^{2}$

Incident Energy $=47.61 / 4,184$

Incident Energy $=11.38 \mathrm{cal} / \mathrm{cm}^{2}$

\section{- $\quad$ BUS 7EMSWGRC}

Perhitungan arus arcing (Ia): $\log \left(\mathrm{I}_{\mathrm{a}}\right)=0,00402+0,983 \log \left(\mathrm{I}_{\mathrm{B}}\right)$

$\log \left(\mathrm{I}_{\mathrm{a}}\right)=0,00402+0,983 \log (72.59)$

$\log \left(I_{a}\right)=1,833, I_{a}=68.11 \mathrm{kA}$

Perhitungan Insiden Energi (E):

En $=10^{K 1+K 2+1,081 \log (I a)+0,0011 G}$

$\mathrm{En}=10^{-0,555+(-0.133)+1,081 \times 1,833+0,0011 \times 153}$

$\mathrm{En}=28.95 \mathrm{~J} / \mathrm{cm}^{2}$

Incident Energy $=4,184 \mathrm{C}_{\mathrm{f}} \operatorname{En}\left(\frac{\mathrm{t}}{0,2}\right)\left(\frac{610^{\mathrm{x}}}{\mathrm{D}^{\mathrm{x}}}\right)$

Incident Energy $=4,184 \times 1 \times 28.95\left(\frac{0,116}{0,2}\right)\left(\frac{610^{0,973}}{910^{0,973}}\right)$

Incident Energy $=47.61 \mathrm{~J} / \mathrm{cm}^{2}$

Incident Energy $=47.61 / 4,184$

Incident Energy $=11.38 \mathrm{cal} / \mathrm{cm}^{2}$

- $\quad$ BUS 7EMSWGRA1

Perhitungan arus arcing (Ia):

$\log \left(\mathrm{I}_{\mathrm{a}}\right)=0,00402+0,983 \log \left(\mathrm{I}_{\mathrm{B}}\right)$

$\log \left(I_{a}\right)=0,00402+0,983 \log (47.1)$

$\log \left(I_{a}\right)=1,648, \quad I_{a}=44.52 \mathrm{kA}$

Perhitungan Insiden Energi $(\mathrm{E})$ :

En $=10^{K 1+K 2+1,081 \log (I a)+0,0011 G}$

$\mathrm{En}=10^{-0,555+(-0.133)+1,081 \times 1,648+0,0011 \times 153}$

$\mathrm{En}=18.27 \mathrm{~J} / \mathrm{cm}^{2}$

Incident Energy $=4,184 \mathrm{C}_{\mathrm{f}} \operatorname{En}\left(\frac{\mathrm{t}}{0,2}\right)\left(\frac{610^{\mathrm{x}}}{\mathrm{D}^{\mathrm{x}}}\right)$

Incident Energy $=4,184 \times 1 \times 18.27\left(\frac{0,116}{0,2}\right)\left(\frac{610^{0,973}}{910^{0,973}}\right)$

Incident Energy $=30.045 \mathrm{~J} / \mathrm{cm}^{2}$

Incident Energy $=30.045 / 4,184$

Incident Energy $=7.181 \mathrm{cal} / \mathrm{cm}^{2}$

\section{- $\quad$ BUS 7EMSWGRA1A}

Perhitungan arus arcing (Ia):

$\log \left(I_{a}\right)=0,00402+0,983 \log \left(I_{B}\right)$

$\log \left(\mathrm{I}_{\mathrm{a}}\right)=0,00402+0,983 \log (47.71)$

$\log \left(I_{a}\right)=1,654 \quad I_{a}=45.11 \mathrm{kA}$

Perhitungan Insiden Energi (E):

En $=10^{K 1+K 2+1,081 \log (I a)+0,0011 G}$

En $=10^{-0,555+(-0.133)+1,081 \times 1,654+0,0011 \times 153}$

$\mathrm{En}=18.54 \mathrm{~J} / \mathrm{cm}^{2}$

Incident Energy $=4,184 \mathrm{C}_{\mathrm{f}} \operatorname{En}\left(\frac{\mathrm{t}}{0,2}\right)\left(\frac{610^{\mathrm{x}}}{\mathrm{D}^{\mathrm{x}}}\right)$

Incident Energy $=4,184 \times 1 \times 18.54\left(\frac{0,116}{0,2}\right)\left(\frac{610^{0,973}}{910^{0,973}}\right)$

Incident Energy $=30.49 \mathrm{~J} / \mathrm{cm}^{2}$

Incident Energy $=30.49 / 4,184$

Incident Energy $=7.28 \mathrm{cal} / \mathrm{cm}^{2}$

- $\quad$ BUS 7EMSWGRB1

Perhitungan arus arcing (Ia):

$\log \left(\mathrm{I}_{\mathrm{a}}\right)=0,00402+0,983 \log \left(\mathrm{I}_{\mathrm{B}}\right)$

$\log \left(\mathrm{I}_{\mathrm{a}}\right)=0,00402+0,983 \log (45.86)$

$\log \left(I_{a}\right)=1,637, I_{a}=43.37 \mathrm{kA}$

Perhitungan Insiden Energi (E): 
$\mathrm{En}=10^{K 1+K 2+1,081 \log (I a)+0,0011 G}$

$\mathrm{En}=10^{-0,555+(-0.133)+1,081 \times 1,637+0,0011 \times 153}$

$\mathrm{En}=17.77 \mathrm{~J} / \mathrm{cm}^{2}$

Incident Energy $=4,184 \mathrm{C}_{\mathrm{f}} \operatorname{En}\left(\frac{\mathrm{t}}{0,2}\right)\left(\frac{610^{\mathrm{x}}}{\mathrm{D}^{\mathrm{x}}}\right)$

Incident Energy $=4,184 \times 1 \times 17.77\left(\frac{0,116}{0,2}\right)\left(\frac{610^{0,973}}{910^{0,973}}\right)$

Incident Energy $=29.23 \mathrm{~J} / \mathrm{cm}^{2}$

Incident Energy $=29.23 / 4,184$

Incident Energy $=6.98 \mathrm{cal} / \mathrm{cm}^{2}$

\section{- $\quad$ BUS 7EMSWGRB1A}

Perhitungan arus arcing (Ia):

$\log \left(\mathrm{I}_{\mathrm{a}}\right)=0,00402+0,983 \log \left(\mathrm{I}_{\mathrm{B}}\right)$

$\log \left(I_{a}\right)=0,00402+0,983 \log (45.86)$

$\log \left(I_{a}\right)=1,637, I_{a}=43.37 \mathrm{kA}$

Perhitungan Insiden Energi (E):

$\mathrm{En}=10^{K 1+K 2+1,081 \log (\mathrm{Ia})+0,0011 G}$

$\mathrm{En}=10^{-0,555+(-0.133)+1,081 \times 1,637+0,0011 \times 153}$

$\mathrm{En}=17.77 \mathrm{~J} / \mathrm{cm}^{2}$

Incident Energy $=4,184 \mathrm{C}_{\mathrm{f}} \operatorname{En}\left(\frac{\mathrm{t}}{0,2}\right)\left(\frac{610^{\mathrm{x}}}{\mathrm{D}^{\mathrm{x}}}\right)$

Incident Energy $=4,184 \times 1 \times 17.77\left(\frac{0,116}{0,2}\right)\left(\frac{610^{0,973}}{910^{0,973}}\right)$

Incident Energy $=29.23 \mathrm{~J} / \mathrm{cm}^{2}$

Incident Energy $=29.23 / 4,184$

Incident Energy $=6.98 \mathrm{cal} / \mathrm{cm}^{2}$

\section{- $\quad$ BUS 7EMSWGRC1}

Perhitungan arus arcing (Ia):

$\log \left(I_{\mathrm{a}}\right)=0,00402+0,983 \log \left(\mathrm{I}_{\mathrm{B}}\right)$

$\log \left(I_{a}\right)=0,00402+0,983 \log (43.21)$

$\log \left(\mathrm{I}_{\mathrm{a}}\right)=1,611 \mathrm{I}_{\mathrm{a}}=40.92 \mathrm{kA}$

Perhitungan Insiden Energi (E):

$\mathrm{En}=10^{K 1+K 2+1,081 \log (I a)+0,0011 G}$

$\mathrm{En}=10^{-0,555+(-0.133)+1,081 \times 1,611+0,0011 \times 153}$

$\mathrm{En}=16.66 \mathrm{~J} / \mathrm{cm}^{2}$

Incident Energy $=4,184 \mathrm{C}_{\mathrm{f}} \operatorname{En}\left(\frac{\mathrm{t}}{0,2}\right)\left(\frac{610^{\mathrm{x}}}{\mathrm{D}^{\mathrm{x}}}\right)$

Incident Energy $=4,184 \times 1 \times 16.66\left(\frac{0,116}{0,2}\right)\left(\frac{610^{0,973}}{910^{0,973}}\right)$

Incident Energy $=27.402 \mathrm{~J} / \mathrm{cm}^{2}$

Incident Energy $=27.402 / 4,184$

Incident Energy $=6.54 \mathrm{cal} / \mathrm{cm}^{2}$

\section{Penentuan Jarak Aman Batas Perlindungan}

Untuk mengkalkulasi jarak aman batas perlindungan, menggunakan persamaan seperti pada persamaan (12).

Flash protection boundary dapat dihitung menggunakan persamaan berikut:

$$
D_{B}=\left[4.184 C_{f} E_{n}\left(\frac{t}{0.2}\right)\left(\frac{610^{x}}{E_{B}}\right)\right]^{\frac{1}{x}}
$$

Keterangan:

$\mathrm{D}_{\mathrm{B}}=$ batas jarak dari titik busur api $(\mathrm{mm})$
$\mathrm{C}_{\mathrm{f}}=$ faktor perhitungan (1.0 untuk tegangan di atas $1 \mathrm{kV}$, 1.5 untuk tegangan di bawah atau sama dengan $1 \mathrm{kV}$ )

$\mathrm{E}_{\mathrm{n}} \quad=$ energi insiden normal

$\mathrm{E}_{\mathrm{B}}=$ energi insiden dalam $\mathrm{J} / \mathrm{cm}^{2}$ pada batas jarak

$\mathrm{t} \quad=$ waktu (detik)

$\mathrm{x} \quad$ = jarak exponen

$\mathrm{I}_{\mathrm{bf}} \quad=$ bolted fault current $(\mathrm{kA})$

$\mathrm{E}_{\mathrm{B}}$ dapat disetting $5.0 \mathrm{~J} / \mathrm{cm}^{2}$ untuk bare skin (no hood) atau rating dari PPE yang diajukan $\left(5.0 \mathrm{~J} / \mathrm{cm}^{2}=1.2\right.$ $\left.\mathrm{cal} / \mathrm{cm}^{2}\right)$.

\section{- $\quad$ BUS 7EMSWGRA}

Perhitungan jarak batas perlindungan (D):

$\mathrm{D}_{\mathrm{B}}=\left[4,184 \operatorname{Cf} \operatorname{En}\left(\frac{\mathrm{t}}{0,2}\right)\left(\frac{610^{\mathrm{x}}}{E_{B}}\right)\right]^{\frac{1}{x}}$

$\mathrm{D}_{\mathrm{B}}=\left[4,184 \times 1 \times 28.95\left(\frac{0,116}{0,2}\right)\left(\frac{610^{0,973}}{5}\right)\right]^{\frac{1}{0,973}}$

$\mathrm{D}_{\mathrm{B}}=9223.07 \mathrm{~mm}=30,25 \mathrm{ft}$

$(1 \mathrm{~mm}=0.00328 \mathrm{ft})$

- $\quad$ BUS 7EMSWGRB

Perhitungan jarak batas perlindungan (D):

$\mathrm{D}_{\mathrm{B}}=\left[4,184 \operatorname{Cf} \operatorname{En}\left(\frac{\mathrm{t}}{0,2}\right)\left(\frac{610^{\mathrm{x}}}{E_{B}}\right)\right]^{\frac{1}{x}}$

$\mathrm{D}_{\mathrm{B}}=\left[4,184 \times 1 \times 28.95\left(\frac{0,116}{0,2}\right)\left(\frac{610^{0,973}}{5}\right)\right]^{\frac{1}{0,973}}$

$\mathrm{D}_{\mathrm{B}}=9223.07 \mathrm{~mm}=30,25 \mathrm{ft}$

- $\quad$ BUS 7EMSWGRC

Perhitungan jarak batas perlindungan (D):

$\mathrm{D}_{\mathrm{B}}=\left[4,184 \operatorname{Cf} \operatorname{En}\left(\frac{\mathrm{t}}{0,2}\right)\left(\frac{610^{\mathrm{x}}}{E_{B}}\right)\right]^{\frac{1}{X}}$

$\mathrm{D}_{\mathrm{B}}=\left[4,184 \times 1 \times 28.95\left(\frac{0,116}{0,2}\right)\left(\frac{610^{0,973}}{5}\right)\right]^{\frac{1}{0,973}}$

$\mathrm{D}_{\mathrm{B}}=9223.07 \mathrm{~mm}=30,25 \mathrm{ft}$

- $\quad$ BUS 7EMSWGRA1

Perhitungan jarak batas perlindungan (D):

$\mathrm{D}_{\mathrm{B}}=\left[4,184 \operatorname{Cf} \operatorname{En}\left(\frac{\mathrm{t}}{0,2}\right)\left(\frac{610^{\mathrm{x}}}{E_{B}}\right)\right]^{\frac{1}{X}}$

$\mathrm{D}_{\mathrm{B}}=\left[4,184 \times 1 \times 18.27\left(\frac{0.116}{0,2}\right)\left(\frac{610^{0,973}}{5}\right)\right]^{\frac{1}{0,973}}$

$\mathrm{D}_{\mathrm{B}}=5746.698 \mathrm{~mm}=18.84 \mathrm{ft}$

- $\quad$ BUS 7EMSWGRA1A

Perhitungan jarak batas perlindungan (D):

$\mathrm{D}_{\mathrm{B}}=\left[4,184 \operatorname{Cf} \operatorname{En}\left(\frac{\mathrm{t}}{0,2}\right)\left(\frac{610^{\mathrm{x}}}{E_{B}}\right)\right]^{\frac{1}{x}}$

$\mathrm{D}_{\mathrm{B}}=\left[4,184 \times 1 \times 18.54\left(\frac{0,116}{0,2}\right)\left(\frac{610^{0,973}}{5}\right)\right]^{\frac{1}{0,973}}$

$\mathrm{D}_{\mathrm{B}}=5833.99 \mathrm{~mm}=19.135 \mathrm{ft}$

- $\quad$ BUS 7EMSWGRB1

Perhitungan jarak batas perlindungan (D):

$\mathrm{D}_{\mathrm{B}}=\left[4,184 \operatorname{Cf} \operatorname{En}\left(\frac{\mathrm{t}}{0,2}\right)\left(\frac{610^{\mathrm{x}}}{E_{B}}\right)\right]^{\frac{1}{x}}$

$\mathrm{D}_{\mathrm{B}}=\left[4,184 \times 1 \times 17.72\left(\frac{0.116}{0,2}\right)\left(\frac{610^{0,973}}{5}\right)\right]^{\frac{1}{0,973}}$

$\mathrm{D}_{\mathrm{B}}=5568.974 \mathrm{~mm}=18.266 \mathrm{ft}$ 


\section{- $\quad$ BUS 7EMSWGRB1A}

Perhitungan jarak batas perlindungan (D):

$\mathrm{D}_{\mathrm{B}}=\left[4,184 \operatorname{Cf} \operatorname{En}\left(\frac{\mathrm{t}}{0,2}\right)\left(\frac{610^{\mathrm{x}}}{E_{B}}\right)\right]^{\frac{1}{X}}$

$\mathrm{D}_{\mathrm{B}}=\left[4,184 \times 1 \times 17.72\left(\frac{0.116}{0,2}\right)\left(\frac{610^{0,973}}{5}\right)\right]^{\frac{1}{0,973}}$

$\mathrm{D}_{\mathrm{B}}=5568.974 \mathrm{~mm}=18.266 \mathrm{ft}$

\section{- $\quad$ BUS 7EMSWGRC1}

Perhitungan jarak batas perlindungan (D):

$\mathrm{D}_{\mathrm{B}}=\left[4,184 \operatorname{Cf} \operatorname{En}\left(\frac{\mathrm{t}}{0,2}\right)\left(\frac{610^{\mathrm{x}}}{E_{B}}\right)\right]^{\frac{1}{X}}$

$\mathrm{D}_{\mathrm{B}}=\left[4,184 \times 1 \times 16.66\left(\frac{0,116}{0,2}\right)\left(\frac{610^{0,973}}{5}\right)\right]^{\frac{1}{0,973}}$

$\mathrm{D}_{\mathrm{B}}=5226.887 \mathrm{~mm}=17.144 \mathrm{ft}$

\section{PENUTUP}

\section{A. Kesimpulan}

Berdasarkan analisa dan simulasi yang dilakukan, maka dapat disimpulkan beberapa hal berikut:

1. Penentuan kategori PPE antara metode kurva batas energi dengan metode standart IEEE 1584-2002 menunjukkan hasil yang sama.

2. Adanya perbedaan pada hasil perhitungan batas jarak aman antara metode kurva batas energi dengan standart IEEE 1584-2002. Hal ini disebabkan karena pada metode kurva batasan energi, tidak memperhitungkan nilai insiden energi serta fault clearing time pada masing - masing bus.

3. Analisa busur api untuk penentuan kategori PPE menggunakan kurva batasan energi ini sesuai dilakukan pada sistem kelistrikan dengan memiliki banyak bus. Karena, metode ini cukup memasukkan karakteristik kurva pengaman pada kurva batasan energi. Sehingga pada perpotongan kedua kurva tersebut dapat ditentukan kategori PPE yang diperlukan.

\section{DAFTAR PUSTAKA}

[1] IEEE Std. 1584-2002. "Guide for Performing Arc flash Hazard Calculations".

[2] Timothy B. Dugan, "Reducing The Arc flash Hazard,"IEEE Industry Application Magazine., May-June 2007

[3] Yasser Moustafa Atwa , "Mitigating Arc-Flash Exposure," IEEE Industry Application Magazine., July-August 2011. 